\title{
New Governors on the Block The Rise of Anti-money Laundering Professionals
}

\author{
Tsingou, Eleni
}

Document Version

Accepted author manuscript

Published in:

Crime, Law and Social Change

DOI:

10.1007/s10611-017-9751-x

Publication date:

2018

License

Unspecified

Citation for published version (APA):

Tsingou, E. (2018). New Governors on the Block: The Rise of Anti-money Laundering Professionals. Crime, Law and Social Change, 69(2), 191-205. https://doi.org/10.1007/s10611-017-9751-x

Link to publication in CBS Research Portal

\section{General rights}

Copyright and moral rights for the publications made accessible in the public portal are retained by the authors and/or other copyright owners and it is a condition of accessing publications that users recognise and abide by the legal requirements associated with these rights.

Take down policy

If you believe that this document breaches copyright please contact us (research.lib@cbs.dk) providing details, and we will remove access to the work immediately and investigate your claim. 


\section{New Governors on the Block: The Rise of Anti-money Laundering Professionals Eleni Tsingou}

Journal article (Accepted version)

CITE: New Governors on the Block : The Rise of Anti-money Laundering Professionals. / Tsingou, Eleni. In:

Crime, Law and Social Change, Vol. 69, No. 2, 03.2018, p. 191-205.

This is a post-peer-review, pre-copyedit version of an article published in Journal of Business Ethics. The final authenticated version is available online at:

https://doi.org/10.1007/s10611-017-9751-x

Uploaded to CBS Research Portal: January २०19 


\title{
New governors on the block: the rise of anti-money laundering professionals
}

\begin{abstract}
Anti-money laundering (AML) activities are part of an institutionalized, global and increasingly prescriptive regime, covering a growing set of predicate offences. Yet with much of the responsibility for implementation and monitoring at the hands of private actors, compliance professionals within financial institutions have become foot soldiers in the fight against money laundering. This paper argues that AML professionals do not only implement and monitor, however, but, to protect their interests, also shape the content of governance. The process is two-fold. First, a professionalization process is underway inside banks and other financial institutions. Professionalization has strengthened the relative standing of compliance departments against a background of lower tolerance for illegal and irregular transactions and a growing reputational and financial cost for banks knowingly or accidentally enabling such activities. From that position, the compliance industry has consolidated its role through the development of systematic professional standards and through identifiable skills and expertise as defined by professional associations. Second, anti-money laundering professionals interpret rules and engage in regulatory creep. They meticulously implement different requirements by developing private compliance standards and risk assessments that are technically sophisticated and designed to earn regulatory kudos; they do not simply follow what is required. Further, they extend their mandate by including other compliance facets. Acting out of concern for professional security and advancement, AML compliance officers become governors on the output, but also on the input side.
\end{abstract}

\section{Keywords}

banking, compliance, governance, money laundering, professions, tax 


\section{Governance as Compliance: The Rise of Anti-Money Laundering Professionals}

This paper examines how an increasingly professionalized compliance industry has emerged in response to increased activity in the global anti-money laundering (AML) regime. Where compliance had long been a 'necessary evil' of a back office activity for financial institutions, the global nature of the AML regime and the reputational and financial cost associated with AML failures gave a new urgency to the compliance function.

The AML regime, built to target the proceeds of crime as a means to tackle the underlying ill (be that drug trafficking, terrorism or, more recently, nuclear proliferation) has long developed at the intersection of professional knowledge and expertise in two distinct groups of policymakers, regulators and law enforcers, who have different training, policy goals and professional aspirations. The regime is thus driven by institutionalization and policy diffusion as manifested by the activities of the Financial Action Task Force (FATF) which are the focus of several contributions to this special issue. The regime, however, is also based on ongoing coordination, socialization and competition among regulation and law enforcement professional networks in the formulation of AML standards. The reconciliation of these professional tensions is in turn played out in the practice of AML by the private sector and within financial institutions. It is the role of compliance officers and departments to meet AML requirements and satisfy regulators and law enforcers alike.

AML activities rely on an extensive legal and regulatory regime, with formal institutions at the international, regional and national levels, and a global reach (Hameiri and Jones 2015; Kerwer and Hüllse 2011; Sharman 2011). Yet much AML activity and governance are practiced through private sector actors, with the role of financial institutions in AML a trend well established in the AML literature (Bergström et al. 2011; Favarel-Garrigues et al. 2011; Tsingou 2010) along with recent work covering a greater range of private actors such as database and software providers whose business models rely on a continuing role for private sector implementation (Liss and Sharman 2015) or who have unwillingly become intermediaries as in the case of legal professionals (Egan 2016). This paper follows in this tradition. While focus on the 'compliance officer' is not new (Favarel-Garrigues et al. 2008, Verhage 2009), this paper goes beyond national cases and looks at the global AML compliance industry which has developed and, crucially, professionalized, in parallel to the formal global AML regime. It also argues that professionalization has led to an extension of governance functions, from implementation, to active interpretation of rules, to shaping the content of governance through regulatory creep.

Since the 1980s, and especially in in the past 15 years, the AML compliance industry developed in three key ways. At the senior level, we observe the phenomenon of revolving doors, especially during the key milestones of the AML regime, mostly from law enforcement agencies (Favarel-Garrigues et al. 2011) and 'Big 4' professional services firms in particular, as compliance departments within financial institutions looked for unique skills and expertise in the areas of investigation and forensic accounting. At the same time, IT and other technical capacity became standardized as a small number of firms provide the necessary software to 
financial institutions. But much transformation has also taken place at the junior and midcareer levels where the compliance industry has been increasingly populated by staff who follow harmonized training and acquire globally recognized qualifications in AML. A number of professional associations were created to provide these services, in turn building a global community of AML compliance experts through internationally recognized qualifications, 'road shows' that include training events, workshops and conferences, and capacity building in less advanced jurisdictions.

These trends reflect the growing importance of compliance functions in the AML regime. The professionalization of AML compliance was bolstered by exogenous factors, first, the terrorist attacks of $9 / 11$ and after the onset of the global financial crisis,, public deficits and attention to tax revenue. In this time, compliance moved from being a back-office activity at odds with the priorities of the business lines of financial institutions; the global nature of the AML regime and the reputational and financial cost associated with AML failures have given credibility and authority to AML compliance staff. The function, prestige and power of compliance professionals are also changing as, despite resistance, compliance now plays a bigger role within financial institutions. The consolidation of this position stems also from compliancedriven regulatory creep and extending competencies to other areas of financial crime, including tax.

The remainder of this paper is organized in five sections. The first section outlines key characteristics of the global AML regime focusing in particular on how aspects of AML public policy rely on the private sector in practice. The second section provides an overview of the methods; the paper is based on research in Europe, North America and Asia, including forty interviews, participant observation at professional association conferences in Europe and North America and document analysis of additional conference material in all three continents. The third section shows how the AML compliance industry has grown and professionalized. The fourth section provides an analysis of the governance role of the industry interpretation, implementation and regulatory creep. It shows that AML professionals are nor simply rule adopters but are also responsible for making rules in practice. In the conclusion, the paper examines the implications of these governance roles in terms of effectiveness and the types of financial relationships and transactions that are being monitored and regulated.

\section{Understanding the global AML regime: of states and markets}

The highly developed legal and regulatory AML activity gives the impression of a state-driven and state-focused regime. Having gone from a thin institutional context in the 1980s to a multilevel institutionalized regime in a short period of time, the AML framework is populated by inter-state cooperation mechanisms and institutions. The significance of state concerns has only intensified since the inclusion of terrorist financing in the AML framework after 2001 and the addition of proliferation of weapons of mass destruction in 2012. 
The focus on states is a starting point in much of the International Relations and International Political Economy literature on money laundering and fits with an understanding of the policy narrative of 'following the money' which straddles financial integrity and security arguments. Work has focused on the club-like organizational qualities of the Financial Action Task Force (FATF) (Drezner 2007), the hegemonic function of the United States (Simmons 2001), and regime formation based on prohibition norms and compliance processes (Andreas and Nadelmann 2006). Other state-centered analyses have looked at the mechanisms and consequences of global diffusion (Sharman 2008; Sharman 2011). The authors in the first section of this special issue make further contributions to the literature on the role of states and state agencies in maintaining momentum for the regime and elaborating the content of AML activities.

The policy priorities mirrored in the activities of FATF are derived from both AML prevention and enforcement goals. Prevention principles are essentially about the development of regulatory tools and the articulation of regulatory and supervisory rules and standards. They promote best practice, standardization and harmonization. Prevention, that is, is about process. Enforcement principles, on the other hand, are about the development of legal tools of investigation, confiscation, prosecution and punishment. Enforcement thus privileges results. FATF's competence and mandate are lopsided, focusing extensively on procedural standards. In public policy terms, the AML regime is most institutionalized, the policies clearest and the actors most transparent on the preventative regulatory side- yet the regime is at its most visible, to the public but also to the business line departments of financial institutions, when a failure occurs and enforcement takes over.

For those practicing AML, expertise needs to satisfy both sides and to deal with the potential competition between professional financial regulatory knowledge and professional legal enforcement knowledge. ${ }^{1}$ Questions of system and framework design arise relating to policy learning, peer reviews and feedback. The tensions between prevention and enforcement can also affect how actors define and deal with acceptable risks (be they reputational, financial or security risks). Nowhere is this more visible than within financial institutions, the actors seen to be at the receiving end of AML rules and left to practice what FATF preaches.

In the history of the AML regime, the role of the private sector, and in particular large financial institutions with significant international activity, is marked by compromise and opportunity (see also Tsingou 2010). Following the criminalization of money laundering in the 1980s and the introduction of initial controls, the somewhat limited measures adopted can be interpreted as an acceptable compromise for financial institutions keen to safeguard capital mobility (Helleiner 1999). For financial institutions, these early measures were a mere extension of

\footnotetext{
${ }^{1}$ Interviews with AML practitioners in the United States over time show an important development on this front. In 2008, interviewees in both the public and private sectors referred to the importance of a legal or law enforcement background and qualifications. Financial institutions focused senior recruitment efforts in those areas as well. In 2013, the stress was on practitioners who understood financial products. For more on the use of interviews in this paper, please see the subsequent section.
} 
existing regulations on bank secrecy and did not threaten the growing rewards to be derived from international financial transactions. In the aftermath of the terrorist attacks of 2001, however, and following the addition of terrorist financing to the AML framework, measures became both more constraining and, in the perception of financial institutions, costly (Harvey 2004). The private sector became accordingly a reluctant participant.

As participants in the regime, financial institutions have straightforward obligations but also incentives to take AML seriously, primarily in relation to reputational and legal risk (Simonova 2011; Verhage 2009). They have established dedicated AML teams, engaged in AML training, and invested in compliance software. Predictably, from the early stages of the AML regime, and especially since the intensification of AML activity after 2001, there has been no shortage of complaining about the cost and lack of cost-effectiveness (KPMG 2014). Though sophisticated 'know your customer' systems can also help finesse a financial institution's business lines activities, the benefits of customer profiling, even for financial institutions well placed to assess customer risk, may be exaggerated. ${ }^{2}$ Incentive structures for the private sector understood in purely financial terms have thus fluctuated based on the political salience of the issue with investment in AML activity continuing to grow through the financial crisis. ${ }^{3}$

There are, however, some areas of concrete private sector growth as a result of the growth of AML activity. AML policies, especially since preoccupations relating to terrorism and proliferation have been added to the mix, have spurred the emergence of a private intelligence industry, including intelligence-led policing. These private actors have the flexibility to work with a variety of relevant agents (journalists, insolvency experts and others), whereas public prosecutors have to maintain higher standards of neutrality. Moreover, the regime has led to the development of data-mining and other techniques which have given private sector actors a key public security role in the context of terrorist financing (de Goede 2012). For-profit growth can also be seen in the activities of firms offering AML-specific training, software and other tangible and 'for sale' AML expertise (Liss and Sharman 2015). These firms are directly linked to a further area of growth (if not profit): AML in-house compliance, with much of the work being done by AML compliance officers trained on the job, and increasingly, through formal accreditation professional programs run by professional associations. These are, at first glance, the 'foot soldiers' of the AML regime; but the way in which this new professional group talks about its functions and trains itself suggests that the AML compliance industry has also carved a more pro-active governance role for itself.

\footnotetext{
2 Interviews with private sector practitioners in all three interview regions suggest that AML professionals are keen on this line of reasoning, but acknowledge that the internal organization of financial institutions prevents serious benefits from materializing.

${ }^{3}$ Interviews with AML compliance practitioners in the private sector in all three regions confirmed continuing investment through the financial crisis.
} 


\section{Methods}

To illustrate this development, the paper focuses on the micro processes of professionalization and looks at the work content of AML compliance. The research relies on interviews and participant observation in the European Union, the United States, and Hong Kong/China as the primary sources of data. Specifically, I conducted semi-structured interviews with forty-one AML practitioners. I conducted interviews with staff in banks, other financial services firms, and staff in professional associations. Among private sector practitioners, interviewees were split between senior AML compliance officers, mid-career staff and recent recruits. To examine how those in the public sector assessed developments in the AML compliance function, I also conducted interviews with regulators and law enforcement officials. All but three of the interviews were conducted in person and all were typically one to two hours in duration. All interviewees were offered anonymity.

Interviews informing this paper took place at several intervals: a first round of interviews took place in March-April 2008 (New York, Washington D.C., London and Luxembourg). By 2008, the banking compliance practices established after 9/11 were in place though not yet mature. Subsequent interviews took place between September 2012 and June 2014, following the height of the global financial crisis, from which banks received greater scrutiny, both for their role in the crisis and for their compliance deficiencies. I conducted an additional interview with a professional association representative in April 2017 for the purposes of acquiring up-to-date information on membership figures and association activities. Interview sites included Amsterdam, Beijing, Hong Kong, London, Luxembourg, Miami, New York and Washington D.C. Interviews with public sector employees and compliance officers began with questions covering AML activity in general before addressing issues related to AML compliance, the growth of the compliance industry, paths to career progression, including qualifications and training, and key professional challenges. Interviews with professional association staff focused on developments in the compliance industry, the type of training on offer, competition among qualification providers, and the global characteristics of AML compliance. Table 1 summarizes organizational and geographical characteristics of the interviewees, as well as the interview timeline.

Table 1: Characteristics of interviewees

\begin{tabular}{|c|c|c|c|c|}
\hline & Public sector & Banks & Financial services & $\begin{array}{c}\text { Professional } \\
\text { association }\end{array}$ \\
\hline European Union & $\begin{array}{c}5 \\
\text { Apr 2008 } \\
\text { Dec 2012 }\end{array}$ & $\begin{array}{c}\text { April 2008 } \\
\text { April 2013 }\end{array}$ & $\begin{array}{c}\text { 3 } \\
\text { Dec 2012 } \\
\text { Apr 2013 }\end{array}$ & $\begin{array}{c}\text { June 2014 } \\
\text { April 2017 }\end{array}$ \\
\hline United States & 5 & 5 & 2 \\
& March 2008 & 5 & March 2008 \\
& Fob 2014 2013 & Fov 2013 2014 \\
\hline Hong Kong/China & 8 & 5 & & 1 \\
& Sep - Oct 2012 & Oct 2012 & & Oct 2012 \\
\hline
\end{tabular}


During the second phase of the research, I also engaged in participant observation at three professional association conferences: the annual 'Anti-money Laundering and CounterTerrorist Financing' European conference of the Association of Certified Anti-Money Laundering Specialists (ACAMS) (Amsterdam, June 2012), the inaugural 'Risk Management' conference of ACAMS (New York, January 2013) and the annual 'Anti-Money Laundering and Compliance' conference of the Florida International Bankers Association (Miami, February 2014). I also had access to conference material and presentations of the ACAMS 5th Annual AML and Financial Crime Conference - Asia Pacific (Bangkok, April 2013). The participant observation entailed following presentations for content but additionally, keeping field notes on questions from the audience, noting professional interactions during breakout sessions and formal networking times, as well as the activities of vendors and other exhibitors. Furthermore, I followed several training webinars organized by ACAMS; this material provided information on training topics and training content.

The interviews were not recorded to permit interviewees greater flexibility in elaborating case examples, and notes were taken by hand while in session and then typed up with additional reflections immediately afterwards. Notes from participant observation and webinars also followed this procedure.

The following sections rely heavily on this material. Unless otherwise stated, observations on developments in the AML compliance function and their effects on regulation apply to practices in all three fieldwork areas and are based on concrete evidence of agreement among interviewees. The data was processed to make sense and analyze: work content in AML compliance; the place of AML compliance in an organization's structure, including reporting lines; expertise in AML compliance; training needs and financial investment in compliance; internal and external expectations about training and skills; career trajectories and financial remuneration. The data was analyzed to account for changes in the above over time.

\section{AML compliance: the coming of age of an accidental profession}

AML compliance is a relatively new field both in terms of work content and with respect to the professionalization and designation of 'AML compliance officer' as a stand-alone career-track position. The growth of AML compliance is a direct result of the development of the AML regulatory regime since the mid-1980s. AML compliance was significantly strengthened after 2001 and the inclusion of terrorist financing in the AML regime; growth maintained momentum through the financial crisis thanks to political pressure to bolster financial integrity. With the proliferation of public rules came an expectation of costs and responsibilities to be borne by the private sector. Rules and regulations (national and global) have been internalized in financial institutions. AML best practice has been learned through policy adoption, but also through learning in formally recognized environments that offer training and accreditation. 
These environments are organized to provide (global) homogeneity in practice and to focus on the professionalization of the AML function.

Homogeneity is being promoted partly through investment in AML infrastructure and in the specification of certain skillsets for top management AML positions. Financial institutions embarked on AML compliance partly through 'importing' knowledge and skills. There are now a small number of software vendors that provide checklists for various types of AML, terrorist financing, proliferation and other risks. The most dominant is World-Check, which provides regularly updated lists of risk-posing individuals, as well as organizations and countries currently facing sanctions (Liss and Sharman 2015). World-Check stays relevant not only through regular updates but also through innovations, such as 'zero footprint screening', which, according to the company, enables financial institutions to screen a transaction or customer without leaving a digital trace with the vendor. World-Check is not a mere compiling tool; it uses existing lists but supplements them with nominations based on in-house research and methodologies (de Goede and Sullivan 2016). With a large majority of financial institutions buying these products, the software leads to increased standardization of AML practice. Additionally, top banks in particular engage in 'revolving doors' hiring, by recruiting retired or senior law enforcement officials with an investigative background, regulators familiar with risk assessment and fines, or forensic accountants from the 'Big 4' professional services firms to senior AML compliance positions. Financial institutions have commonly hired former regulators (c.f. Shive and Forster 2016) but reaching out to senior officials in law enforcement is a new development.

While bringing in skills and infrastructure is important, the professionalization of AML is mostly happening among the junior and mid-level staff populating ever larger AML compliance departments. This group is at the center of claims to 'jurisdictions' (Abbott 1988) which establish what issues are relevant and should be addressed, what tasks are to be performed, and who has the right to and is responsible for performing them. In contrast to the cases often discussed in the sociology of professions literature, however, this professional group did not emerge through formal university training, and recognition by states and markets of its usefulness (cf. Abbott 1988). Rather, the development of this accidental profession is a story of opportunity for those literate in finance, accounting or law. Instead of deferring to the standards of their professions by university training to deal with the demand for compliance, they created their own. They did so through 'institutional work', where agents delimit their own field and boundaries, strategize to define their roles vis-à-vis others and use expertise as a tool to prevent others from encroaching on their turf (c.f. Currie et al. 2012; Lefsrud and Meyer 2012).

Indeed, a growing number of AML compliance officers are now certified, the vast majority of them through one organization, the Association of Certified Anti-Money Laundering Specialists (ACAMS). ACAMS was established in 2002 and offers specialized training seminars, thematic conferences and online training in all areas pertaining to money laundering (including various 
types of white collar crime, tax fraud and tax evasion, and sanctions). It is as of 2016 owned by Becker Professional Education, specialists in certification and continuing education with a strong track record in accountancy certifications. The training is expensive but interviewees in the private sector claimed it was relatively easy; ${ }^{4}$ courses and discussions are deliberately practical. Exams offer multiple choice answers but have become more difficult over time (the pass rate is deliberately kept lower than $80 \%$ ) but the majority of the answers can be found in the guide. ${ }^{5}$ The cost of training is habitually borne by employers. ACAMS certification (Certified Anti-Money Laundering Specialist or CAMS), or the willingness to be certified, is now a common requirement in recruitment and there are discussions among regulators (strongly encouraged by ACAMS) to make certification of some kind a formal requirement in AML units. There are direct benefits for AML compliance officers too. Surveys have shown a notable increase in salary after certification (ACAMS 2013) and CAMS is essential for career advancement. ${ }^{6}$ The CAMS qualification is also perceived by staff as useful for holding court with a financial institution's top management which considers AML predominantly as cost. The shadow of hierarchy is indeed an important element in the development and consolidation of AML compliance. Bank practices have to follow global rules but within a bank, the compliance officer is the unloved and often irritating distraction from the real business of making money.

My participant observation indicates that the learning environment in ACAMS training events is, despite much emphasis on the practical, a fairly top-down affair and quite repetitive, more conference-style than classroom. Accreditation is through attendance of various events and webinars, culminating in the examination. Though formal AML rules are not accompanied by specific prescriptive practices, in a training environment, there are 'right' ways and 'wrong' ways to practice AML. Conference presentations have a zero-risk rhetoric that is seldom replicated in the questions and answers sessions where practical discussions include an element of learning about how to cover one's back.

In preparing for the exam, practitioners have course guides that spell out steps in anti-money laundering and likely scenarios and loopholes. Training also provides model documentation for tracking suspicious activity and offers examples of model internal organizational structures. It also stresses the importance of understanding the banking business models and products so as to best liaise and convince other departments.

In interactive training situations, the students are given flashcards to test their knowledge of AML policies with each other and to work through solutions to common money laundering problems and scenarios. The purpose of the flashcards is to simulate live responses to AML policy dilemmas as well as prepare for the exam. Those leading the discussions are either formally affiliated with ACAMS or, on occasion, leading practitioners from the large financial

\footnotetext{
4 Thirteen out of the eighteen private sector professionals interviewed held a certification or had undertaken some training. All interviewees in the United States and Hong Kong were found to be certified.

5 Interview with ACAMS Executive Vice-President, February 2014.

${ }^{6}$ A point reiterated by all interviewees; certification is important both for in-house promotions and for being 'poached'.
} 
institutions. The resulting qualification is thus based on harmonized training and an ACAMSapproved definition of the appropriate professional skills. To maintain CAMS status, practitioners need to have their skills and regulatory knowledge evaluated regularly. In addition to CAMS, ACAMS now offers more advanced training and is exploring various tie-ins with higher education institutions. It also has a short introductory foundation program. ${ }^{7}$

ACAMS started in the United States, and close to half of the association's approximately 45,000 members (up from about 20,000 at the beginning of the decade) are US-based practitioners. But the association is growing world-wide. ACAMS is the primary provider of certification in Asia and the Middle East and is making inroads in Europe and Latin America. Its exams are available in Arabic, Japanese, Mandarin, French, Spanish, Portuguese and Russian (with German and Bahasa forthcoming). ACAMS organizes annual regional conferences and frequent country seminars. Additionally, it encourages networking and community-building through local association chapters. The membership is made up mostly by AML compliance officers working in banks, but also includes practitioners in other private sector institutions, as well as some regulators. ${ }^{8}$

The dominance of ACAMS and the credibility of its certification (recognized by interviewees across organizational types) have made CAMS the qualification benchmark. But like with any good professional association story, this dominance is not uncontested. ACAMS faces soft competition from qualifications offered by national banking associations, from the more academic but also broader qualifications of the International Compliance Association and, closer to home, by the Association of Certified Financial Crime Specialists (ACFCS), which also goes beyond AML. The latter was set up by the original founder of ACAMS and is now run by a legal education company. It markets more aggressively than ACAMS and is gaining members, but without threatening the position of ACAMS as a specialist qualifications provider and a focused hub of AML expertise.

The role of ACAMS and membership associations more generally is important in the next steps of the professionalization process. Professional associations act as venues that enable social interactions which define appropriate conduct, behavioral responsibilities, and membership credentials (Greenwood et al. 2002). By establishing shared standards and some heavy-duty moral values, at least in the case of AML, these venues shape a community identity. AML compliance professionals will seek things that look the same, and form status groups accordingly. This crystallizes a sense of identity further, and creates peer networks across institutions and legal jurisdictions. It helps with jostling for position within a financial institution when trying to make the compliance case to top management, but can also blind AML professionals to lapses in the practices of other professionals in their network (c.f. Gabbioneta et al. 2014).

\footnotetext{
${ }^{7}$ More information on certification, developments in training, and fees can be found at http://www.acams.org/.

${ }^{8}$ Interview with ACAMS staff member, April 2017.
} 
Recognized certification, claims to unique expertise, and the standardization of activities as promoted by professional associations such as ACAMS also serve to boost AML compliance as a project of institutionalization (Suddaby and Viale 2011). AML compliance professionals have carved a space for themselves within financial institutions and introduced their own ways of working, in turn securing the boundaries of their work. The next step is for them to further consolidate this position and safeguard their professional status and career prospects .

\section{New Governors on the Block}

There is no shortage of actors who can claim authority in the governance of anti-money laundering. Starting with FATF, this special issue provides a comprehensive account of who the actors are and where they stand, and makes sense of their interests and motivations. Several papers in the special issue also share this paper's focus on the importance of the role of private actors participating in the governance of the regime. This paper argues specifically that private actors, specifically AML compliance professionals working within financial institutions and backed by a professional membership association, are not only responsible for implementing AML rules but also affect the content of governance. This is not a mere question of expert knowledge or capture, as is the common story when assessing private influence of regulatory processes (Lindblom 1977). This section shows that in defining their tasks and methods, AML professionals interpret rules and shape standards; this is a standard story of the implementation and compliance phase of the governance process. It will also show, however, that AML professionals do more to affect content by expanding the scope of AML governance.

The development has been gradual and reflects the regular changes in the AML regime as dictated by FATF recommendations and the successive waves of their world-wide adoption. In the early years of FATF, the role of the AML compliance officer was still marginal and unlikely to be a full-time position. It proceeded to become a position akin to other compliance functions, based on holding updated information about the regulatory status quo, and potentially benefitting from advice from professional services firms. But in the past fifteen years, the role has been transformed. AML compliance now demands skills of assessment, prevention and preemption that require structures and standardized competences. It is about knowing what the rules say, how they are understood by public officials and how they should be interpreted in practice. It is about having tools such as World-Check at your disposal but also being able to customize your program with investigative ability and checking news stories, social media, and other outlets. And it is also about having the qualifications that act as markers of this knowledge.

At a minimum, qualified compliance departments are in a stronger position to defend themselves both within the financial institution and vis-à-vis examiners. An AML professional is not only technologically savvy and product aware, but he/she also knows how to store information and document decisions, 'if it isn't written down, it didn't happen' being a common 
mantra. ${ }^{9}$ For most professionals, however, the ambition is higher. As has been shown in previous studies, AML compliance practitioners in financial institutions are involved in the coproduction of economic intelligence. They also manage information. They follow the rules, but by being procedurally aware, they have the potential to sabotage the system by overloading it (Favarel-Garrigues et al. 2008).

Being pro-active also leads to providing content to the governance of AML. In the history of the AML regime, private sector benchmarking has gone hand in hand with official activity, most notably through the work of the Wolfsberg Group. A small number of financial institutions large enough to have the resources and organizational capacity to take the lead and set standards established the Wolfsberg Group of Banks, which currently consists of Banco Santander, Bank of America, Bank of Tokyo-Mitsubishi UFJ, Barclays, Citigroup, Credit Suisse, Deutsche Bank, Goldman Sachs, HSBC, J.P. Morgan Chase, Société Générale, Standard Chartered Bank and UBS. The group was created in 2000 and issues AML guidelines for international private banks, at first covering the weak point of correspondent banking relationships but expanding its work to include guidelines on matters such as screening and monitoring of clients and transactions. This is a voluntary code of conduct driven by an apparent need to harmonize for competition reasons and to strengthen private sector reputation and credibility (Pieth and Aiolfi 2003). These exercises in benchmarking evolve from the experience of practicing AML within financial institutions and serve to create a perception of authoritative expertise (Broome and Quirk 2015).

Beyond this type of publicly open benchmarking initiative, however, there are also day-to-day practices and decisions taken by AML professionals who shape the content of AML governance; eventually professional practice can alter regulatory requirements in what amounts to regulatory creep. Specifically, AML compliance professionals within financial institutions have learned to interpret and act upon the rules and guidelines of regulatory agencies partly through anticipating and preempting regulatory expectations. They have learned to manage regulatory reactions to by giving examiners more than is required, or by translating standards into rules.

There are many examples of regulatory creep in the world of AML compliance. One way is to extend compliance coverage by following emerging areas with potential for AML treatment and make strategic decisions about which issues matter before any regulatory consensus has formed (in AML compliance circles, this is also referred to as 'not looking back'). ${ }^{10}$ But the bulk of content shaping and regulatory creep takes place in areas already under regulatory oversight. A case in point here is the fate of risk-based approaches to AML. To address widespread concerns and better reflect the diverse AML realities and risks facing different financial institutions, FATF has made a strong case for a risk-based approach in its recommendations. The approach is intended to promote discretion and better targeting of

\footnotetext{
${ }_{9}^{9}$ Participant observation suggests that the mantra is seldom omitted from presentations on best practice.

${ }^{10}$ Interviews with bank AML compliance practitioners in the 2012-2013 fieldwork period.
} 
resources, and places responsibility on national authorities and financial institutions for determining risk profiles and using judgement in defining requirements.

For financial institutions, employing risk management mechanisms and internal models is not a new regulatory position (Tsingou 2015). There is also an established tradition of modelling risks which challenge the limits of what can be quantified to include judgements on herd behavior, human error, and where data might be contested (see for example, 'the invention of operational risk', Power 2005). In this context, risk is not good or bad, just something to be managed. The practice of AML within financial institutions has challenged this; where risk management and risk assessment are about calculations and determining risk appetite, training material and participant observation show that AML compliance is taught and learned in ways that stress risk aversion. Away from the 'classroom' and in their financial institutions, AML compliance officers are then asked to obtain risk intelligence and develop risk mitigation strategies; yet there are no credible institutional incentive structures for them to do so and to thus challenge their zero-risk tolerance training. Modelling AML transaction monitoring along the lines of other risk types (market risk or credit risk, for example) and expecting reliable and quantifiable validation in doing so is widely considered to be of limited use. ${ }^{11}$ The typical risk assessment process is based on decision trees covering products, customer base and geography, the latter often being an overriding factor. In practice, within their financial institution, AML compliance professionals need to check whether the risk tolerance framework they deem appropriate is compatible with the risk appetite of the business lines. It rarely is, the risk appetite of the business lines being consistently higher. When an examiner visits, on the other hand, the talk is not about the intricacies and merits of the risk assessment model (there are no prizes to be won for having the best one) but rather, of the more pragmatic-sounding likelihood of having a failure, no matter how small, on one's watch.

Investing in a sophisticated risk-based approach thus fails to give AML compliance much kudos with top management or with regulators. The result has been a pronounced preference for a policy of de-risking. AML compliance professionals have interpreted AML standards as more prescriptive rules, leading to regulatory creep. In addition, they have developed programs that are not required (such as a framework of quality assurance for AML compliance practice) but which examiners remark positively upon. Once a program is mentioned in a written report, it is understood that it cannot be undone without penalty. And if an examiner has seen such a program in one financial institution, they might demand it from others. ${ }^{12}$ The activities of AML compliance professionals have therefore essentially formalized a heavier regulatory burden for financial institutions.

\footnotetext{
${ }^{11}$ Interviews with bank and financial services firms AML compliance practitioners in the 2012-2013 fieldwork period.

12 This spiral was identified as an instance of regulatory creep in interviews with US officials in both the public and private sectors.
} 
Regulatory creep is also being given a boost through the strengthening of AML compliance departments within financial institutions. Enforcement actions and continuous scandals have been good news for AML compliance professionals. In the past, to make their case, they had to stress the threat to an institution's reputation. But reputational risk is hard to quantify and in an era of client mobility, large financial institutions have become less concerned about client retention. Accumulated fines in the past ten years, however, have been big enough to make the cost-effectiveness argument more plausible. ${ }^{13}$ The period following a publicized enforcement action is a good time to approach top management with analysis and requests for more funding. Comparisons with competitor practices can in this case act as peer arbitrage. This is also the right moment to remind other departments within a bank or financial services firm of the importance of keeping AML compliance staff happy. Enforcement actions, even when critical, often stress the quality of the staff; when that is not the case, they stress the importance of training. Examiners also value staff retention. Finally, and importantly, enforcement actions can crystallize practices beyond what is formally required as they bring questions of personal liability (for example in relation to senior management) and board accountability into focus.

Regulatory creep is helping consolidate the position of AML compliance professionals and is changing the content of governance. Further consolidation comes from a gradual extension of competencies. In the aftermath of the financial crisis, a focus on financial integrity and sounder corporate governance benefited the position of AML compliance departments. While the LIBOR scandal, for example, had little to do with the role of the private sector in the governance of money laundering, it produced a regulatory environment responsive to compliance issues and added political salience to public rhetoric about the responsibilities of banks. AML compliance professionals have a track record of embracing such opportunities; in the past, they have enthusiastically embarked on activities linked to corruption, fraud or tax (see also Amicelle 2013). This is in line with a FATF focus on a wider range of crimes as predicate offences for money laundering, ranging from trafficking and smuggling, to tax evasion. While dealing with tax issues at a global level and with a globally agreed framework is still very much work in progress, the introduction of the US Foreign Account Compliance Act (FATCA) has brought the issue to the fore for financial institutions outside the United States. FATCA targets banks (not based in the United States) suspected of conspiring with wealthy US citizens to hide their bank accounts from the tax authorities (Palan and Wigan 2014). FATCA is not part of the AML compliance framework and is a unilateral policy, but many of the tools employed to deal with the resulting requirements, are in practice, closely linked to AML provisions. AML compliance professionals, especially in Europe, have been eager adopters of these new responsibilities.

\section{Conclusion}

\footnotetext{
${ }^{13}$ A point stressed by practitioners in the public and private sectors in Europe and the US. Private sector AML compliance officers in Hong Kong remained concerned about reputational issues.
} 
Private sector compliance is a major element of AML governance. Financial institutions are the agents practicing AML governance in their interpretation and implementation of the rules. They are also spaces where, in AML compliance departments, AML frameworks are designed and standards are shaped. This paper has argued that this provides AML professionals a governance function that goes beyond mere compliance; the agents in charge of the 'doing' end up shaping the content of governance too. This is driven by the professionalization of AML compliance functions, first through the emergence and then the consolidation of the AML compliance professional as a viable, even desirable, career choice. These professionals have seen their career prospects drastically improve and are keen to keep this going. They may be agnostic about global hierarchies but are happy to reduce AML governance to legible categories through their use of lists and rules. But they also engage in an institutional project which consolidates their position and functions within financial institution, engaging in regulatory creep and extending the scope of the issue areas under their control.

The story of AML compliance professionals is one that covers the micro side of AML governance. In the AML compliance offices of a financial institution, or the ballrooms hosting ACAMS conferences, what matters is procedure: having good systems, good people and good training that will not let the institution or the profession down. Spending on AML compliance is an ongoing affair for financial institutions so costs matter but there is little talk of the effectiveness or legitimacy of the regime as a whole. The professionalization of AML compliance does not lead to better techniques for 'following the money' but rather, judgements about whose money can be visible. In terms of fighting crime, this is akin to the old story about the drunk who looks under the lamppost for his keys, even when he knows that they are in the dark. The AML compliance profession supplies the lamppost engineers. 


\section{References}

Abbott, A. (1988). The system of professions. Chicago: University of Chicago Press.

Amicelle, A. (2013). Differential management of economic and financial illegalisms: anti-money laundering and 'tax issues'. Penal Field, 10, 1-27.

Andreas, P. and Nadelmann, E. (2006). Policing the globe: criminalization and crime control in International Relations. New York: Oxford University Press.

Bergström, M., Svedberg Helgesson, K. and Mörth, U (2011). A new role for for-profit actors? The case of anti-money laundering and risk management. Journal of Common Market Studies, 49(5), 1043-1064.

Broome, A. and Quirk, J. (2015). Governing the world at a distance: the practice of global benchmarking. Review of International Studies, 41(5), 819-841.

Currie, G., Lockett, A., Finn, R., Martín, G., and Waring, J. (2012). Institutional work to maintain professional power: recreating the model of medical professionalism. Organization Studies, 33, 937-962.

de Goede, M. (2012). Speculative security: the politics of pursuing terrorist monies. Minneapolis: University of Minnesota Press.

de Goede, M. and Sullivan, G. (2016). The politics of security risks. Environment and Planning D: Society and Space 34(1), 67-88.

Drezner, D. W. (2007). All politics is global: explaining international regulatory regimes. Princeton, NJ: Princeton University Press.

Egan, M. (2016). Policing intermediaries in the EU anti-money laundering framework, European Journal of Policing Studies 4 (1), 125-145.

Favarel-Garrigues, G., Godefroy, T. and Lascoumes, P. (2008). Sentinels in the banking industry: private actors and the fight against money laundering in France. British Journal of Criminology 48(1), 1-19.

Favarel-Garrigues, G., Godefroy, T. and Lascoumes, P. (2011). Reluctant partners? Banks in the fight against money laundering and terrorism financing in France. Security Dialogue, 42(2), 179-196.

Gabbioneta, C., Prakash, R. and Greenwood, R. (2014). 'Sustained corporate corruption and processes of institutional ascription within professional networks'. Journal of Professions and Organization, 1(1), 16-32. 
Greenwood, R., Suddaby, R. and Hinings, C. R. (2002). 'Theorizing change: the role of professional associations in the transformation of institutional fields'. Academy of Management Journal 45(1), 58-80.

Hameiri, S. and Jones L. (2015). Regulatory regionalism and anti-money-laundering governance in Asia. Australian Journal of International Affairs, 69(2), 144-163.

Harvey, J. (2004). Compliance and reporting issues arising for financial institutions from money laundering regulations: a preliminary cost benefit study. Journal of Money Laundering Control $7(4), 333-346$.

Helleiner, E. (1999). State power and the regulation of illicit activity in global finance. In R.H. Friman and P. Andreas (eds.), The illicit global economy and state power (pp. 53-90), Lanham, Boulder, New York, Oxford: Rowman \& Littlefield.

Kerwer, D and Hüllse, R. (2011). How international organizations rule the world: the case of the Financial Action Task Force on money laundering. Journal of International Organizations Studies, 2(1), 50-67.

KPMG (2014) Global anti-money laundering survey.

Lefsrud, L. M. and Meyer, R. E. (2012). Science or science fiction? Professionals' discursive construction of climate change. Organization Studies, 33, 1477-1506.

Lindblom, C. E. (1977). Politics and markets: the world's political economic systems. New York: Basic Books.

Liss, C. and Sharman. J.C. (2015). Global corporate crime-fighters: private transnational responses to piracy and money laundering. Review of International Political Economy, 22(4), 693-718.

Palan, R. and Wigan, D. (2014). Herding cats and taming tax havens: the US strategy of 'not in my backyard. Global Policy, 5(3), 334-343.

Pieth, M. and Aiolfi G. (2003). The private sector becomes active: the Wolfsberg process. Journal of Financial Crime, 10(4), 359-365.

Power, M. (2005). The invention of operational risk. Review of International Political Economy, 12(4), 577-599.

Sharman, J.C. (2008). Power and discourse in policy diffusion: anti-money laundering in developing states. International Studies Quarterly, 52(3), 635-656.

Sharman, J.C. (2011). The money laundry: regulating criminal finance in the global economy. Ithaca: Cornell University Press. 
Shive, S. A. and Forster, M. M. (2016). The Revolving Door for Financial Regulators. Review of Finance. doi:10.1093/rof/rfw035.

Simmons, B. (2001). The international politics of harmonization: the case of capital market regulation. International Organization, 55(3), 589-620.

Simonova, A. (2011). The risk-based approach to anti-money laundering: problems and solutions. Journal of Money Laundering Control, 14(4), 346-358.

Suddaby, R. and Viale, T. (2011). Professionals and field-level change: Institutional work and the professional project. Current Sociology, 59(4), 423-442.

Tsingou, E. (2010). Global financial governance and the developing anti-money laundering regime: what lessons for International Political Economy? International Politics, 47(6), 617637.

Tsingou, E. (2015). Club governance and the making of global financial rules. Review of International Political Economy, 22(2), 225-256.

Verhage, A. (2009). Between the hammer and the anvil? The anti-money laundering complex and its interactions with the compliance industry. Crime, Law and Social Change, 52(1), 9-32. 